\title{
Assessment of eye doses to staff involved in interventional cardiology procedures in Kuwait
}

\author{
Meshari Alnaaimi ${ }^{1}$ (D) Mousa Alduaij ${ }^{1} \cdot$ Faisal Shenawy $^{1} \cdot$ Musab Algaily $^{1} \cdot$ Talal Mohammedzein $^{1}$. \\ Mohamed Shaaban ${ }^{2} \cdot$ Madan M. Rehani $^{3}$
}

Received: 13 December 2020 / Accepted: 24 July 2021 / Published online: 5 August 2021

(c) The Author(s), under exclusive licence to Springer-Verlag GmbH Germany, part of Springer Nature 2021

\begin{abstract}
In this study, which is the first of its kind in the gulf region, eye doses of interventional cardiologists and nurses were measured using active dosimeters for left and right eyes, in 60 percutaneous coronary interventions in three main hospitals in Kuwait. The dose given in terms of $\mathrm{H}_{\mathrm{p}}(0.07)$ per procedure when ceiling suspended screens were used by main operators ranged from 18.5 to $30.3 \mu \mathrm{Sv}$ for the left eye and from 12.6 to $23.6 \mu \mathrm{Sv}$ for the right eye. Taking into account typical staff workload, the results show that the dose limit of $20 \mathrm{mSv} / \mathrm{year}$ to the eyes can be exceeded for interventional cardiologists in some situations, which demonstrates the need of using additional effective radiation protection tools, e.g. protective eye spectacles, in addition to the regular and proper use of ceiling suspended screens. With indications of increase in workload, the need for availability of a dedicated active dosimeter for the regular monitoring of eye doses is emphasized.
\end{abstract}

Keywords Eye doses $\cdot \mathrm{Hp}(0.07) \cdot$ Active dosimeters $\cdot$ Interventional cardiology $\cdot$ Radiation protection

\section{Introduction}

In recent years, there has been growing use of X-ray fluoroscopy in clinical departments outside the main imaging departments (Rehani et al. 2010). Unfortunately, in these departments—at least in the gulf region—clinicians such as interventional cardiologists, electro-physiologists, vascular surgeons, urologists, orthopedic surgeons, gastroenterologists, to name a few, typically lack of training in radiation protection. This might pose some radiation-related risks to patients and staff. Recent studies have demonstrated eye lens opacities among 38 to $53 \%$ of main operators and 21 to $45 \%$ of nurses in cardiac catheterization (cath) labs (Rehani et al. 2011; Ciraj-Bjelac et al. 2010; 2012; Vano et al. 2010; 2016). These lens opacities have the potential to lead to cataracts later in life. The observation on the prevalence of eye

Meshari Alnaaimi

m.alnaaimi@gmail.com

1 Radiation Physics Department, Kuwait Cancer Control Centre (KCCC), Shuwaikh, Kuwait City, Kuwait

2 Radiation Protection Department, Shuwaikh, Kuwait City, Kuwait

3 Massachusetts General Hospital, Boston, USA lens opacities among cath lab staff prompted a number of research activities worldwide. For occupational exposure, the International Commission on Radiological Protection (ICRP) has recently reduced the annual dose limit to the eye lens by a factor of 7.5 from 150 to $20 \mathrm{mSv}$ (Stewart et al. 2012). A recently published study indicates that $44 \%$ of interventional cardiologists would exceed the annual limit if eye protection tools are not utilized (Domienik-Andrzejewska et al. 2020).

Nearly 13.5 million interventional procedures were performed in the US in 2016, the number of fluoroscopy-guided cardiac intervention was 4.1 million (Mettler et al. 2020). In Kuwait, there are more than five thousand interventional procedures performed every year as per data of 2009 (Tsapaki et al. 2009). At the moment, no information is available on eye doses for staff working in interventional procedures in Kuwait, and there is a similar lack of information from neighboring countries in the region. With increasing emphasis on radiation-induced cataracts and reduction in threshold dose for the lens of the eye, there is a need to assess the radiation doses to staff working in interventional procedures in Kuwait. To meet this demand, the International Atomic Energy Agency (IAEA) has supported Kuwait through a technical cooperation (TC) project KUW9009 which aims at assessing radiation doses to eyes of medical and paramedical 
staff involved in interventional procedures in Kuwait. In addition, this TC project promotes optimization in radiological protection by providing the required scientific data and input for developing related guidelines for the healthcare personnel exposed to recurrent doses of ionizing radiation to the eye lenses.

\section{Materials and methods}

Under the framework of TC project KUW9009, a detailed work plan for dose measurements, data collection and analysis was developed. To that end, an IAEA expert mission was organised to evaluate the collected data and recommend protective measures for reducing eye radiation doses. The study was carried out in cardiac catheterization laboratories of three hospitals in Kuwait, namely, Chest Diseases Hospital, Al-Salam Hospital, and Mubarak Hospital. The study was approved by the ministry of health institutional ethical review board before the commencement of data collection. Data on technical parameters, workload, use of radiation protection devices, use of personal dosimeters and exposure history were collected. The study covered only percutaneous coronary intervention (PCI) procedures performed in the participating centers. Informed consent was obtained from all participants. Interventional cardiology procedures are usually performed by a team consisting of two cardiologists and a nurse/technician working in close proximity to the patient as shown in Fig. 1. The interventional cardiologist is the main operator who performs the procedure assisted by a second cardiologist and a nurse. During these cardiac procedures there is some variability in the work practice and position of the nurses compared to the positions of the cardiologists.

The three sites included in the present study used a Philips BV Pulsera fluoroscopic unit with a typical range for the tube voltage of $40-110 \mathrm{kV}$. These units are subjected to regular quality control. Staff workload varies, but roughly 10-20 PCI procedures are performed weekly with a fluoroscopy time ranging between 8 and $12 \mathrm{~min}$ and a pulsed fluoroscopy set at 7.5 pulses per second and cine recording with a cine rate of 15 to 20 frames per second. The kerma-areaproduct (KAP) generated for each procedure using the KAP meter incorporated in the imaging system was also recorded. Ceiling suspended screens and table mounted lead curtains were used for radiation shielding. No protective lead spectacles were available. Simple statistical analysis was performed using Microsoft Excel (Microsoft Office Pro Plus 2019).

ED3 (Rotunda, USA) active personal extremity dosimeters were used for real-time dose monitoring. Currently, commercial electronic dosemeters for eye dose assessment are not available, and ED3 was the only electronic dosimeter available for the present study. The ED3 makes use of

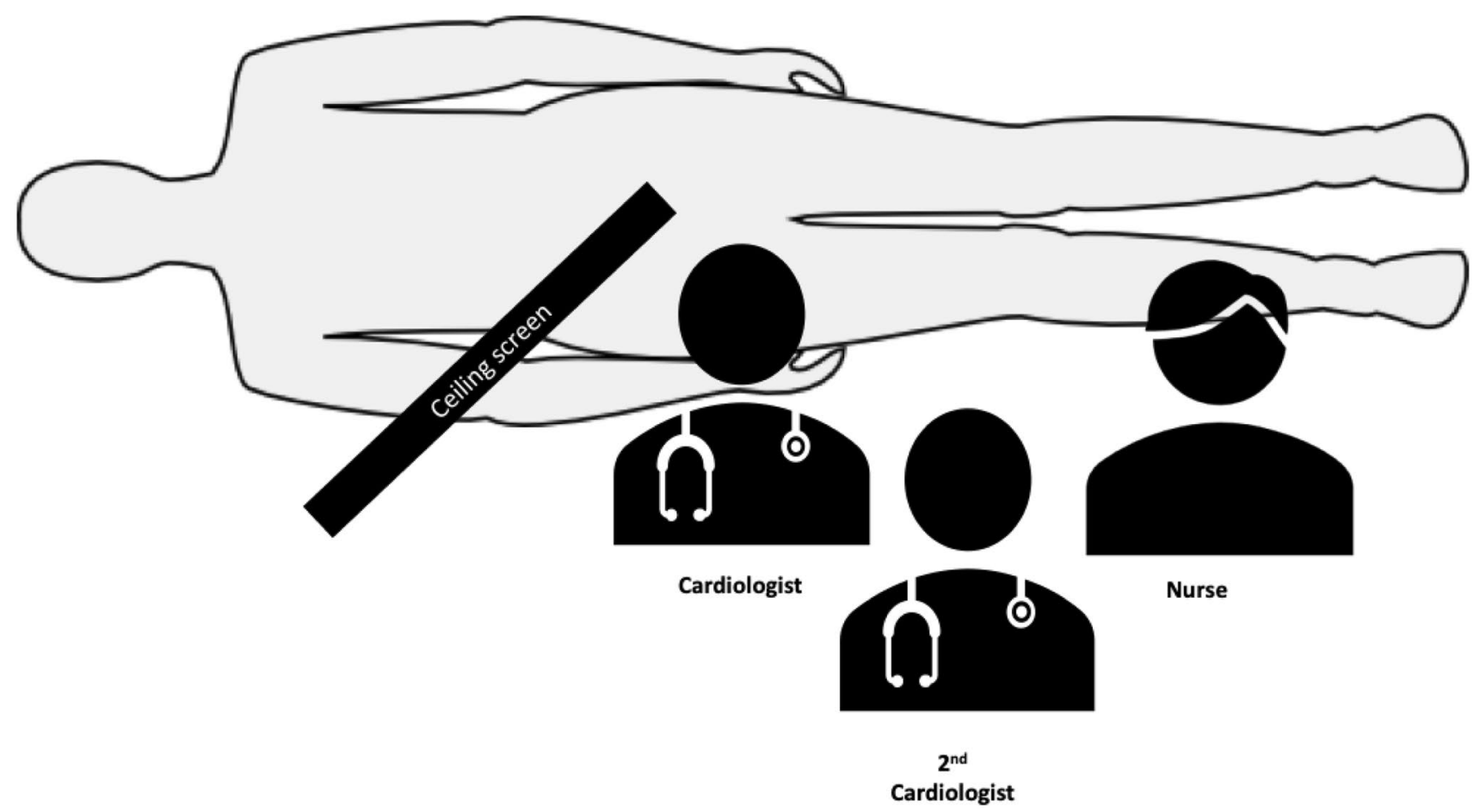

Fig. 1 The usual positions of staff during percutaneous coronary intervention (PCI) procedures. The position of the ceiling suspended screen is also indicated but varies with the operator 
Silicon diodes to measure $\mathrm{H}_{\mathrm{p}}(0.07)$ for a photon energy range from $60 \mathrm{keV}$ up to $1.25 \mathrm{MeV}$ with $\pm 30 \%$ angular response (Rotunda Scientific Technologies 2017). Until October 2019 there was no International Electrotechnical Commission (IEC) standard for pulsed X-ray testing and thus the calibration provided by the company was for gamma rays only. Two ED3 detectors were placed one each on the right and left side of the eyes using a head strap, or were clipped to the regular spectacles. The detectors, although calibrated for $\mathrm{H}_{\mathrm{p}}(0.07)$, provided reasonable estimates of the doses delivered to the lens of the eyes, even though $\mathrm{H}_{\mathrm{p}}(3)$ would be ideal (Behrens and Dietze 2010; Carinou et al. 2015; Vano et al. 2015 and Ginjaume et al. 2019). Specifically, the $\operatorname{Hp}(0.07)$ and the $\mathrm{Hp}(3)$ eye doses measured are comparable within 15\% (Ciraj-Bjelac and Rehani 2014). The number of available ED3 dosimeters for this study was limited. Consequently, eye doses were measured separately for cardiologists and nurses in the three different hospitals leading to a total of 60 monitored procedures.

The eye lens doses were estimated by taking the median values of the occupational doses per procedure measured with the ED3 dosimeters in a sample of PCI procedures at the same hospital. The eye lens dosses were then normalized to patient doses by dividing measured $\mathrm{H}_{\mathrm{p}}(0.07)$ to respective KAP values. Annual eye doses were estimated by multiplying the dose per procedure with the annual workload of PCI procedures. Finally, the results were compared to results from other countries.

Another objective of the KUW9009 project was to increase radiation protection awareness among interventional cardiology staff. Several training courses, seminars, webinars, and radiation safety expert site visits were organised. The key components of the implemented training actions were radiation protection, optimizing of work practice, eye lens doses monitoring and reduction. Training in radiation protection is the most desirable and successful action to reduce occupational doses (Vano et al. 2016). Additionally, for clinicians who were not interested in any technical details a simplified version of the training material was developed as a mobile app that provides a higher level of outreach than more detailed training material. The eye radiation dose app "ERD" developed as part of the present project includes a quick link to guidelines, training materials and an eye dose calculation tool. When clicking the "dose calculator" tab the app invites the user to select the type of procedure and simply add the annual workload, to get an estimate of the annual eye radiation dose. This is done by taking into account typical staff doses per procedure available at the IAEA radiation protection website (IAEA 2017). The results are displayed in a color-coded index to alert users when the level of eye lens radiation exposure is high compared to the ICRP dose limit. The app is freely available and can be downloaded at https://erd.com.kw.
Table 1 Summary of measured eye doses per procedure in a sample of percutaneous coronary intervention $(\mathrm{PCI})$ procedures at hospitals $\mathrm{A}, \mathrm{B}$, and $\mathrm{C}$

\begin{tabular}{lccl}
\hline \multicolumn{1}{c}{$\begin{array}{l}\text { Chest } \\
\text { diseases } \\
\text { hospital } \\
(\mathrm{A})\end{array}$} & $\begin{array}{l}\text { Al-Salam hospital } \\
(\mathrm{B})\end{array}$ & $\begin{array}{l}\text { Mubarak hospital } \\
(\mathrm{C})\end{array}$ \\
\hline \multicolumn{2}{c}{ Right-eye dose $(\mu \mathrm{Sv})$} \\
Cardiologists & $23.6 \pm 5.4$ & $17.6 \pm 3.2$ & $12.6 \pm 2.9$ \\
Nurses & $2.4 \pm 1.1$ & $5.3 \pm 1.3$ & $1.8 \pm 0.5$ \\
Left eye dose $(\mu \mathrm{Sv})$ & & \\
Cardiologists & $30.3 \pm 4.7$ & $23.9 \pm 2.6$ & $18.5 \pm 2.1$ \\
Nurses & $2.9 \pm 1.4$ & $7.1 \pm 1.8$ & $2.4 \pm 0.3$ \\
\hline
\end{tabular}

Shown are median values of occupational eye lens doses measured during ten procedures for cardiologists and ten for nurses at the same hospital, and corresponding standard deviations

Table 2 Eye doses in the presence of ceiling suspended screen normalised to respective KAP for cardiologists

\begin{tabular}{|c|c|c|c|}
\hline Hospital & A & B & $\mathrm{C}$ \\
\hline Average cumulative FT ( $\mathrm{min}) /$ procedure & 11.8 & 8.7 & 9.2 \\
\hline $\mathrm{KAP}\left(\mathrm{Gy} \cdot \mathrm{cm}^{2}\right)$ & 92.2 & 76.9 & 78.7 \\
\hline Number of procedures/hospitals & 20 & 20 & 20 \\
\hline Cardiologist average eye dose/procedure $(\mu \mathrm{Sv})$ & 30.3 & 23.9 & 18.5 \\
\hline Cardiologist eye dose/KAP ( $\left.\mu \mathrm{Sv} / \mathrm{Gy} . \mathrm{cm}^{-2}\right)$ & 0.329 & 0.311 & 0.235 \\
\hline
\end{tabular}

The left-eye dose values, the mean fluoroscopy time (FT), the mean kerma area product (KAP) and the number of procedures $(n)$ in chest diseases hospital (A), Al-Salam hospital (B), and Mubarak hospital (C)

\section{Results}

Table 1 shows the eye doses measured during PCI procedures in the investigated cardiac catheterization laboratories. For cardiologists the dose per procedure range from 18.5 to $30.3 \mu \mathrm{Sv}$ for the left eye and from 12.6 to $23.6 \mu \mathrm{Sv}$ for the right eye.

The average fluoroscopy time, KAP, eye dose values and eye dose values normalized to the corresponding KAP during PCI procedures are presented in Table 2. The overall average value of KAP during the investigated PCI procedures for cardiologists was $82.6 \mathrm{~Gy} . \mathrm{cm}^{2}$ (based on individual average values in three hospitals of 92.2, 76.9, 78.7). The ratio of main operator eye lens dose to KAP in the presence of ceiling suspended screen was 0.292 (range 0.235-0.329) $\mu \mathrm{Sv} / \mathrm{Gy} . \mathrm{cm}^{2}$.

The estimated annual doses-based on a workload of 1,000 fluoroscopy guided PCI procedures performed yearly in Kuwait-are shown in Fig. 2. As a result, for the left eye lens dose a value of $30.3 \mathrm{mSv}$ was estimated, 


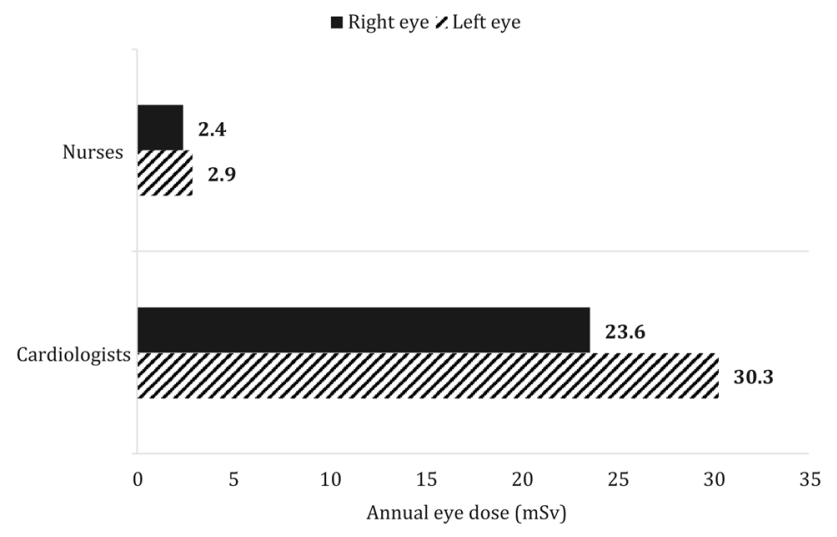

Fig. 2 Estimated annual eye lens doses, based on a typical annual workload of 1,000 percutaneous coronary intervention (PCI) procedures, for interventional cardiologists and nurses working at Chest Diseases Hospital compared to the annual dose limit of $20 \mathrm{mSv} / \mathrm{y}$ as recommended by ICRP and implemented in Kuwait

while for the right eye lens dose a value of $23.6 \mathrm{mSv}$ was estimated. Thus, the estimated annual eye dose received by cardiologists in Kuwait might exceed the dose limit recommended by ICRP and implemented in Kuwait.

Table 3 compares eye doses reported in recent publications as compared to those obtained in the present study.

\section{Discussion}

This is the first study not only in Kuwait but also in the whole gulf region assessing eye doses to staff involved in percutaneous coronary interventions using active personal dosimeters. Eye lens doses were estimated based on typical workload of medical staff involved in those procedures. The results obtained indicate that doses to the lenses of the eyes of the cardiologists can potentially exceed the ICRP annual dose limit, which necessitates actions to reduce eye lens doses. Those actions could include wearing lead spectacles in addition to improving the placement of ceiling suspended screens, in addition to the optimization of techniques to reduce patient doses which will have direct implications on staff doses.

PCI procedures usually result in high-radiation exposure to patients and staff. The radiation dose to the lens of the eye varied widely in the present study which is not unexpected. This is mainly due to differences in staff skills, experience, radiation protection awareness and work environment. Table 1 show that the cardiologist dose during PCI procedures range between 18.5 and $30.3 \mu \mathrm{Sv}$ for the left eye and between 12.6 and $23.6 \mu \mathrm{Sv}$ for the right eye. When compared with other studies (Table 3 ) the present results are within the range observed by others and are rather in good agreement.

The results show that the doses to the left eye are higher than those to the right eye, which is expected as demonstrated by other investigators (Antic et al. 2013; Kim et al. 2008; Häusler et al. 2009). Lower doses to eye lens were found for nurses compared to cardiologists (Fig. 2), which is expected because nurses usually stand away from the X-ray beam at the patient foot end (Fig. 1). In contrast to the main operator, nurses have a greater degree of flexibility in terms of their location with respect to the patient, which can make a big difference in eye lens dose. In some situations, however, the nurses need to be very close to the patients during
Table 3 Comparison of published data on average eye doses during percutaneous coronary intervention (PCI) procedures for interventional cardiologists

\begin{tabular}{|c|c|c|c|}
\hline Authors & Country & $\begin{array}{l}\text { Detector } \\
\text { type }\end{array}$ & $\begin{array}{l}\text { Eye dose } \\
\text { per proce- } \\
\text { dure } \\
(\mu \mathrm{Sv})\end{array}$ \\
\hline Vanhavere et al. (2011) & Belgium & $\begin{array}{l}\text { Thermoluminescent dosimeter } \\
\text { (TLD) }\end{array}$ & $40-60$ \\
\hline Antic et al. (2013) & Serbia & $\begin{array}{l}\text { Unfors Educational Direct Dosimeter } \\
\text { (EDD30) }\end{array}$ & 121 \\
\hline Vano et al. (2016) & Spain & $\begin{array}{l}\text { Optically stimulated luminescence } \\
\text { (OSL) }\end{array}$ & 296 \\
\hline Krisanachinda et al. (2017) & Thailand & $\begin{array}{l}\text { Optically stimulated luminescent dosimeter } \\
\text { (OSLD) }\end{array}$ & 157 \\
\hline Rizk et al. (2018) & Lebanon & $\begin{array}{l}\text { Thermo Scientific Double Chipstrate EXT- } \\
\text { RAD Extremity Dosimeters } \\
\text { (EXTRAD) }\end{array}$ & 15 \\
\hline Sánchez et al. (2020) & Spain & $\begin{array}{l}\text { Optically stimulated luminescent dosimeter } \\
\text { (OSLD) }\end{array}$ & 10 \\
\hline Current study (2021) & Kuwait & $\begin{array}{l}\text { Rotunda Scientific } \\
\text { Extremity Dosimeter } \\
\text { (ED3) }\end{array}$ & 30 \\
\hline
\end{tabular}

The dose values $\mathrm{H}_{\mathrm{p}}(0.07)$ for the left eye were measured with ceiling suspended screens but without protective spectacles, or were measured outside the protective spectacles 
a cardiac procedure, which makes it difficult to protect them properly against the radiation. This could possibly explain why nurses in hospital B showed three times higher doses than those in the other hospitals (Table 1).

In interventional cardiology procedures the eye dose depends on many factors that usually vary during those procedures. The correlation between patient and staff eye doses has been studied in recent years (Antic et al. 2013). For example, it has been shown that typically $1 \mathrm{~Gy} . \mathrm{cm}^{2}$ of KAP to the patient results in an estimated average dose to the lens of the eye of $10 \mu \mathrm{Sv}$ due to scatter dose at a C-arm (Leyton et al. 2016). By applying radiation protection measures, the eye dose due to scattered radiation can be reduced by up to 6\%, at a C-arm (Vano et al 2016). Variations in fluoroscopy time and KAP were observed (Table 2), which were probably due to the complexity of the procedure and the experience of the cardiologist, because similar systems were used for all measurements. The eye lens doses to cardiologists in hospital A were higher than those in other hospitals. This is evidenced by the highest fluoroscopy time, which could be due to more complex procedures performed in hospital, a dedicated cardiac center, as compared to those performed in the other investigated hospitals. Variations of eye lens doses due to the influence of parameters like procedure complexity, technical parameters and proper positioning of ceiling suspended screens need further investigations.

Taking into account the typical annual workload of staff performing PCI procedures the estimated value of eye dose for interventional cardiologists can reach up to $30 \mathrm{mSv}$ per year, highlighting the need for either additional lead spectacles or optimal placement of ceiling suspended screens and procedure parameters. Similar estimates made for nurses result in eye doses of about $3 \mathrm{mSv} / \mathrm{year}$. For interventional cardiologists in Kuwait, doses to the lens of the eye thus exceed the annual eye dose limit.

Table 3 summarizes published data on eye doses during PCI procedures. The comparison demonstrates that the average dose per procedure for the main operator ranges from $10 \mu \mathrm{Sv}$ up to $300 \mu \mathrm{Sv}$. This indicates that eye exposure levels associated with cardiology procedures vary in different countries. With current workloads and lack of proper radiation protective measures the annual dose limit is likely to be exceeded also in countries other than Kuwait.

Personal protective equipment is very effective in reducing eye doses, particularly when combining ceiling suspended screens with lead spectacles. The use of lead spectacles-with a thickness of $0.5 \mathrm{~mm}$ or $0.7 \mathrm{~mm}$ lead equivalence- has a small but meaningful effect on eye dose depending on photon energy, while other key parameters like beam projection, procedure geometry and correct use of available radiation protection equipment are more effective (Koukorava et al. 2014). Using ceiling suspended screens with lead spectacles can reduce eye lens dose by $83-90 \%$
(Matsubara et al. 2020), while using side shields or 'wrap around' eyewear can reduce the dose by $74 \%$ and $21 \%$ for the left and right eyes, respectively (Koukorava et al. 2014). When using leaded spectacles the impact of dosimeter position on the measured dose is great. The dosimeters should be very close to the eye and unshielded by the spectacles, to avoid underestimation of eye lens dose (Honorio da Silva et al. 2020). Eye dose calculation tools can be used to estimate the effectiveness of using radiation protection equipment and optimize the eye protection (Covens et al. 2018).

The lack of monitoring the occupational doses in interventional cardiology and the lack of the regular use of personal dosimeters and radiation protection tools has already been emphasized earlier in an international survey (Padovani et al. 2011). The situation is similar in Kuwait and in the gulf region. Indeed, there is a need to strengthen radiation protection awareness and occupational monitoring with emphasis to eye dose monitoring. For that reason, a mobile app "ERD" was developed as an awareness tool that can be used for optimisation of working practices and estimation of cumulative eye lens doses based on the number of performed procedures. The ERD app can be used for risk assessment and retrospective estimation of eye lens doses to health professionals who are likely to receive doses higher than 3/10th of the annual dose limit (Dauer et al. 2017).

The limitations of the present study include the following: one limitation is the lack of appropriate electronic active personal dosimeters for eye lens dose evaluation. The ED3 dosimeters, even though not specifically designed for eye lens dosimetry, is the only currently available electronic dosimeter that can be used for an estimation of eye lens doses. ED3 dosimeters are uncomfortable for the daily use during PCI procedures but are better than any passive dosimeters with head band. Also, the dose estimates in the present study do not take into account any other procedures the staff might be involved in. Even though the contribution of such other procedures to eye lens doses may be small, it will add up to the already high doses interventional cardiologists receive. Another limitation is the fact that the measurements were not performed simultaneously for cardiologist and nurses, due to the limited number of available dosimeters. In addition, the estimated workload used in the present study is based on an earlier publication from 2009 (Tsapaki et al. 2009); since then the number of PCI procedures has been increasing, and the current workload may be much higher. Finally, further studies on aspects identified in this study could not be pursued in view of the COVID19 pandemic. For example, the current study would have benefited from a better assessment of the location of the nurse in different hospitals, because the preliminary information available did not allow to explain the high eye doses of nurses in hospital B as compared to those in the other two hospitals. Assessment of an appropriate placement of ceiling 
suspended screens is a difficult task. In addition, there is a lack of literature on this issue as most publications tend to just mention the importance of this aspect rather than assessing it in more detail.

Despite these limitations, it is clear that the present study has provided convincing evidence for the need for a better radiation protection of interventional cardiologists and associated staff in Kuwait.

\section{Conclusions}

In the present study, eye lens doses to interventional cardiology staff were measured for the first time in Kuwait and in gulf region as a whole. The doses per procedure for the left eye of the main operator when ceiling suspended screens were used ranged between 18.5 and $30.3 \mu \mathrm{Sv}$ for the left eye, and between 12.6 and $23.6 \mu \mathrm{Sv}$ for the right eye. The results show that the ICRP annual eye lens dose limit of $20 \mathrm{mSv}$ can be exceeded for an annual workload of 1000 PCIs for interventional cardiologists. This demonstrates the need for additional radiation protection optimization measures. In addition, regular radiation protection training and awareness for interventional cardiology staff is needed to reduce eye lens doses.

Acknowledgements The project was funded partially by the Kuwait Foundation of the Advancement of Sciences under project code (PR1713NR-01). The project was supported by the International Atomic Energy Agency (IAEA) through the technical cooperation project KUW9009 "Minimizing the Risk of Radiation Cataractogenesis Among Medical Workers in Kuwait".

Author contributions This submission complies with ethical guidelines and all authors contributed to this manuscript.

\section{Declarations}

Conflict of interest All authors declare that there is no conflict of Interest.

\section{References}

Antic V, Ciraj-Bjelac O, Rehani M, Aleksandric S, Arandjic D, Ostojic M (2013) Eye lens dosimetry in interventional cardiology: results of staff dose measurements and link to patient dose levels. Radiat Prot Dosim 154(3):276-284. https://doi.org/10.1093/rpd/ncs236

Behrens R, Dietze G (2010) Monitoring the eye lens: which dose quantity is adequate? Phys Med Biol 55(14):4047-4062. https://doi. org/10.1088/0031-9155/55/14/007

Carinou E, Ferrari P, Ciraj-Bjelac O, Gingaume M, Merce M, Oconnor U (2015) Eye lens monitoring for interventional radiology personnel: dosemeters, calibration and practical aspects of $\mathrm{H} \mathrm{p} \mathrm{(3)}$ monitoring. A 2015 review. J Radiol Prot 35(3):R17-R34. https:// doi.org/10.1088/0952-4746/35/3/R17

Ciraj-Bjelac O, Rehani MM (2014) Eye dosimetry in interventional radiology and cardiology: current challenges and practical considerations. Radiat Prot Dosimetry 162(3):329-337.https://doi.org/ $10.1093 / \mathrm{rpd} / \mathrm{nct} 291$

Ciraj-Bjelac O, Rehani M, Sim KH, Liew HB, Vano E, Kleiman NJ (2010) Risk for radiation-induced cataract for staff in interventional cardiology: is there reason for concern? Catheter Cardiovasc Interv 76(6):826-834. https://doi.org/10.1002/ccd.22670

Ciraj-Bjelac O, Rehani M, Minamoto A, Sim KH, Liew HB, Vano E (2012) Radiation-induced eye lens changes and risk for cataract in interventional cardiology. Cardiology 123(3):168-171. https:// doi.org/10.1159/000342458

Covens P, Dabin J, De Troyer O, Dragusin O, Maushagen J, Struelens L (2018) Track, calculate and optimise eye lens doses of interventional cardiologists using MEyeDose and MEyeDose_X. J Radiol Prot 38(2):678-687. https://doi.org/10.1088/1361-6498/aab2e4

Da Silva E, Martin C, Vanhavere F, Buls N (2020) A study of the underestimation of eye lens dose with current eye dosemeters for interventional clinicians wearing lead glasses. J Radiol Prot 40(1):215-224. https://doi.org/10.1088/1361-6498/ab55ca

Dauer LT, Hamada N, Blakely E (2017) National council on radiation protection and measurements commentary number 26 : impact of revised guidance on radiation protection for the lens of the eye. J Am Coll Radiol 14(7):980-982. https://doi.org/10.1016/j.jacr. 2017.05.003

Domienik-Andrzejewska J, Brodecki M, Zmyślony M (2020) Correlation of eye lens doses and personal dose equivalent measured on the arm of interventional cardiologists for a retrospective assessment of doses to operators' eye lens. Radiat Prot Dosim 189(3):271-278. https://doi.org/10.1093/rpd/ncaa039

Ginjaume M, Carinou E, Brodecki M, Clairand I, Domienik-Andrzejewska J, Exner L, Ferrari P, Jovanović Z, Krstic D, Principi S, Van Hoey O, Vanhavere F (2019) Effect of the radiation protective apron on the response of active and passive personal dosemeters used in interventional radiology and cardiology. J Radiol Prot 39(1):97-112. https://doi.org/10.1088/1361-6498/aaf2c0

Häusler U, Czarwinski R, Brix G (2009) Radiation exposure of medical staff from interventional X-ray procedures: a Multicentre Study. Eur Radiol 19(8):2000-2008. https://doi.org/10.1007/ s00330-009-1388-4

IAEA, RPOP (2017) Radiation protection of medical staff from cataract. https://www.iaea.org/resources/rpop/healthprofessionals/ radiology/cataract/staff.

Kim KP, Miller DL, Balter S, Kleinerman RA, Linet MS, Kwon D, Simon SL (2008) Occupational radiation doses to operators performing cardiac catheterization procedures. Health Phys. 94(3):211-227. https://doi.org/10.1097/01.HP.0000290614. 76386.35

Krisanachinda A, Srimahachota S, Matsubara K (2017) The current status of eye. lens dose measurement in interventional cardiology personnel in Thailand. Radiol Phys Technol 10(2):142-147. https://doi.org/10.1007/s12194-017-0403-8

Koukorava C, Farah J, Struelens L, Clairand I, Donadille L, Vanhavere F, Dimitriou P (2014) Efficiency of radiation protection equipment in interventional radiology: a systematic monte carlo study of eye lens and whole-body doses. J Radiol Prot 34(3):509-528. https:// doi.org/10.1088/0952-4746/34/3/509

Leyton F, Nogueira MS, Gubolino LA, Pivetta MR, Ubeda C (2016) Correlation between scatter radiation dose at height of operator's eye and dose to patient for different angiographic projections. Appl Radiat Isot 117:100-105. https://doi.org/10.1016/j.aprad iso.2016.01.013

Matsubara K, Takei Y, Mori H, Kobayashi I, Noto K, Igarashi T, Suzuki S, Akahane K (2020) A multicenter study of radiation 
doses to the eye lenses of medical staff performing non-vascular imaging and interventional radiology procedures in Japan. Phys Med 74:83-91. https://doi.org/10.1016/j.ejmp.2020.05.004

Mettler A, Mahesh M, Bhargavan-Chatfield M, Chambers C, Elee J, Frush D, Miller D, Smith J, Vetter R (2020) Patient exposure from radiologic and nuclear medicine procedures in the united states: procedure volume and effective dose for the period 2006-2016. Radiology 295(2):418-427. https://doi.org/10.1148/radiol.20201 92256

Padovani R, Le Heron J, Cruz-Suarez R, Duran A, Lefaure A, Miller D, Sim H, Vano E, Rehani M, Czarwinski R (2011) International project on individual monitoring and radiation exposure levels in interventional cardiology. Radiat Prot Dosim 144(1-4):437-441. https://doi.org/10.1093/rpd/ncq326

Rehani M, Ciraj-Bjelac O, Vano E, Miller D, Walsh S, Giordano B, Persliden J (2010) ICRP publication 117 radiological protection in fluoroscopically guided procedures performed outside the imaging department. Ann ICRP 40(6):1-102. https://doi.org/10.1016/j. icrp.2012.03.001

Rehani M, Vano E, Ciraj-Bjelac O, Kleiman N (2011) Radiation and cataract. Radiat Prot Dosim 147(1-2):300-304. https://doi.org/ 10.1093/rpd/ncr299

Rizk C, Farah J, Fares G, Vanhavere F (2018) Occupational doses for the first and second operators in lebanese interventional cardiology suites. Radiat Prot Dosim 182(4):438-447. https://doi.org/ 10.1093/rpd/ncy085

Rotunda scientific technologies, LLC (2017) ED3 extremity dosimeter. https://www.rotundascitech.com/products/ed3-extremity-dosim eter.

Sánchez RM, Vano E, Fidalgo J, Fernandez JM (2020) Percutaneous structural cardiology: are anaesthesiologists properly protected from ionising radiation? J Radiol Prot 40(4):1420-1428. https:// doi.org/10.1088/1361-6498/abc4d7

Stewart A, Akleyev A, Hauer-Jensen M, Hendry J, Kleiman N, Macvittie T, Aleman B (2012) ICRP publication 118: ICRP statement on tissue reactions and early and late effects of radiation in normal tissues and organs. Ann ICRP 41(1-2):1-322. https://doi.org/10. 1016/j.icrp.2012.02.001

Tsapaki V, Ahmed N, Alsuwaidi J, Beganovic A, Benider A, BenOmrane L, Rada B, Kharita M, Khelassi-Toutaoui N, Manatrakul N, Mirsaidov I, Shaaban UI, Wambani S, Zaman A, Ziliukas J, Zontar D, Rehani M (2009) Radiation exposure to patients during interventional procedures in 20 countries: initial IAEA project results. Am J Roentgenol 193(2):559-569. https://doi.org/10. 2214/AJR.08.2115

Vanhavere F, Carinou E, Domienik J, Donadille L, Ginjaume M, Gualdrini G, Koukorava C, Krim S, Nikodemova D, Ruiz-Lopez N, Sans-Merce M, Struelens L (2011) Measurements of eye lens doses in interventional radiology and cardiology: Final results of the ORAMED project. Radiat Meas. https://doi.org/10.1016/j. radmeas.2011.08.013

Vano E, Kleiman N, Duran A, Rehani M, Echeverri D, Cabrera M (2010) Radiation cataract risk in interventional cardiology personnel. Radiat Res 174(4):490-495. https://doi.org/10.1667/ RR2207.1

Vano E, Sanchez RM, Fernandez JM (2015) Estimation of staff lens doses during interventional procedures. Comparing cardiology, neuroradiology and interventional radiology. Radiat Prot Dosim 165(1-4):279-283. https://doi.org/10.1093/rpd/ncv049

Vano E, Fernandez J, Resel L, Moreno J, Sanchez R (2016) Staff lens doses in interventional urology. A comparison with interventional radiology, cardiology and vascular surgery values. J Radiol Prot 36(1):37-48. https://doi.org/10.1088/0952-4746/36/1/37

Publisher's Note Springer Nature remains neutral with regard to jurisdictional claims in published maps and institutional affiliations. 